\title{
Inquietações amazônidas: considerações para uma abordagem enativa da comunicação
}

\section{Amazonians concerns: considerations for enactive approach to communication}

\section{Sandro Adalberto Colferai}

Doutor em Sociedade e Cultura na Amazônia (UFAM); mestre em Comunicação Social (PUCRS); licenciado em Letras (UNIR); professor de Jornalismo (UNIR-Vilhena). Membro dos grupos de pesquisa Mapa Cultural de Rondônia (UNIR) e Interfaces (UFAM). <sandrocolferai@gmail.com>

\section{Gilson Vieira Monteiro}

Doutor em Ciências da Comunicação (USP); mestre em Administração (USP); bacharel em Jornalismo (UFAM); professor da Universidade Federal do Amazonas.

<sgilsonvieiramonteiro@yahoo.com>

\section{RESUMO}

O artigo parte de inquietações provocadas, na pesquisa em comunicação na Amazônia, pelas práticas de populações tradicionais que não fazem distinção entre domínios sociais e naturais. A opção é pela corporalidade da comunicação e considera as consequências desta abordagem ao assumir o conceito de enação nas interações mediadas pela tecnologia. As motivações emergem da consideração da inseparabilidade entre natureza e sociedade, que se impõem na intersecção entre o campo da Comunicação e as sociedades amazônidas, que ao fazerem uso de aparatos tecnológicos de comunicação acionam modos de interação diversos daqueles da sociedade ocidental. Deste ponto argumentamos por uma abordagem da comunicação numa perspectiva de mútua atuação entre natureza e sociedade.

Palavras-chave: Comunicação na Amazônia. Corporalidade da Comunicação. Interação na Comunicação.

\begin{abstract}
This paper begins with caused concerns in communication research in the Amazon, by the practices of traditional populations that do not distinguish between social and natural areas. Theoption is the corporeality of communication and considers the consequences of this approach by taking the concept of enaction in interactions mediated by technology. The motivations emerge from consideration of the inseparability of nature and society, which are necessary at the intersection between the field of Communication and Amazonian societies, by making use of technological communication devices trigger several modes of interaction of those of Western society. From this point argued by a communication approach with a view to mutual action between nature and society.
\end{abstract}

Keywords: Communication in the Amazon. Corporeality in communication. Interaction in the Communication.

\section{Introdução}

Neste artigo partimos da percepção de que é possível pôr novos olhares sobre bases epistemológicas que admitem a emergência de novas compreensões do fazer científico, que permite aproximar campos disciplinares separados por um modelo de ciência tradicional. Nesta perspectiva é preciso reconhecer que ideias que se coloquem numa concepção transdisciplinar, como o que apresentamos a seguir, podem ser encaradas como estando no contra fluxo de esforços que buscam alcançar especificidades do campo da 
Comunicação a partir - mesmo que não de maneira exclusiva - da mediação realizada por aparatos de comunicação. Tais esforços têm alcançado êxitos, e alicerçar argumentos outros em princípios transdisciplinares não é o mesmo que se posicionar contrariamente, mas antes constituir argumentos a de inquietações e de possíveis caminhos para ultrapassá-las'.

As inquietações a que nos referimos são aquelas percebidas no contato com diferentes demandas sociais e naturais com que nos deparamos no lugar onde temos desenvolvido nossos trabalhos, a região Norte do Brasil, a Amazônia brasileira. O reconhecimento das particularidades das interações em pequenas comunidades às margens de rios; das populações tradicionais; dos contatos entre aqueles que chegam à Amazônia e aqueles que nela estão há séculos; dos estranhamentos e rearranjos nas periferias das grandes cidades da região; dos usos híbridos das tecnologias de comunicação numa região de geografia desafiadora, com longas distâncias e diferentes noções de tempo e espaço; e de como as mensagens postas em circulação pelos suportes tecnológicos penetram nos cotidianos das pessoas, são algumas da razões para inquietação. Outras razões estão na apreensão de que o meio natural em que todas estas relações se efetivam não é inerte, não é mera paisagem, mas se constitui em elemento fundamental para compreender as interações entre seres humanos, mas não apenas entre estes, mas entre seres vivos, e aí é preciso reconhecer a inseparabilidade entre o humano e a natureza. Tratase de relações ecossistêmicas, mas também de relações comunicacionais que envolvem, inclusive, a comunicação mediada pelos meios. Estas interações comunicacionais são inapartáveis das interações naturais, o que é amplificado pela tecnologia.

As relações ecossistêmicas que consideravam a inseparabilidade entre o homem e a natureza foram tornadas legítimas a partir da argumentação de pensadores das mais diferentes disciplinas, que tem suas ideias postas sob diferentes denominações - Nova Ciência, Paradigma da Complexidade, Biologia do Conhecer, Novo Paradigma da Ciência... Em seus princípios mais básicos estas ideias não são estranhas aos amazônidas, pois estes têm nas relações com o ambiente um dos pontos fundamentais de sua constituição como sociedade, e as interações tornadas legítimas por populações milenares encontram ressonâncias nas sociedades amazônidas contemporâneas² ${ }^{2}$. Este é o

1 Aqui não pensamos em novos posicionamentos que descartam os anteriores, mas em desdobramentos que agregam novas abordagens.

2 Aqui é necessário destacar que, ao contrário do que visões estereotipadas sobre a Amazônia brasileira fazem crer, a região - que perfaz mais da metade do território nacional - apresenta diferentes 
lugar de onde partimos, e de onde propomos a discussão sobre a possibilidade de não se pensar tais relações somente a partir do simbólico acionado pelos seres humanos, mas também ampliar esta perspectiva de maneira a considerar as relações ecossistêmicas. Pensamos na corporalidade das relações ecossistêmicas e comunicacionais para alcançar as interações enativas que possibilitem a superação do "eu" cartesiano pelo "nós" necessário a uma nova ética das interações. E nesta nova ética o "nós" é entendido não apenas como uma junção do "eu" e do "outro", mas também como nós, pontos nodais, da rede de interconexões pessoais e da interação entre humanos, natureza e tecnologias.

\section{Palco amazônico}

As estreitas ligações milenares entre o ser humano e a natureza na Amazônia são reconhecidas desde os primeiros relatos sobre a região feitos por exploradores europeus ainda no século XVI. O regime das cheias e vazantes que dita o tempo circular, a penetração da fauna no cotidiano, os mitos indígenas que não diferenciam o elemento humano dos animais, das plantas ou dos astros, sempre estiveram presentes nestes relatos, mesmo que tenham servido de justificativa para a ação civilizatória por parte dos estados europeus modernos. Os primeiros relatos já apresentam imagens da Amazônia que dão a ideia da amplitude espacial, exuberância da natureza e dos sofrimentos infringidos por esta mesma natureza ao ser humano, que deveria por isso subvertê-la. A partir do final do século XVIII e ao longo de todo o século XIX naturalistas, também europeus, percorrem a região. Um deles, responsável por ajudar a destruir as ideias de uma região de clima infernal e imprópria para a civilização, foi Alfred Russel Wallace. Em meados do século XIX Wallace publica Viagens pelos Rios Amazonas e Negro, em que discute a influência do meio geográfico para a distribuição das espécies animais, inaugurando um ramo da ciência reconhecido como zoogeografia (Pinto, 2008). Mesmo que tenha contribuído para ultrapassar ideias estereotipadas sobre a região, Wallace não superou o princípio de determinação natural.

As determinações naturais efísicas ainda estavam presentes nas traduções da Amazônia feitas no início do século XX, e que tem nos textos de Euclides

configurações societárias e mesmo distinções naturais. A Amazônia mais visível é a da floresta e das calhas dos grandes rios, mas há também as regiões de campos, ao norte, as grandes cidades, como Belém e Manaus, e áreas de colonização agrícola, ao sul. As populações não são apenas a cabocla e a indígena, pois há os grupos urbanos ligados aos complexos agrícolas, como ocorre no sul do Pará e em Rondônia, por exemplo. Tais diferenças intrarregionais da Amazônia são discutidas por Carlos Walter Porto-Gonçalves (Porto-Gonçalves, 2005). 
da Cunha seu principal exemplo. Para Cunha (2003) a paisagem invariável, as distâncias que separam a região do resto do mundo, e o tempo que passa lento, acabam por contagiar o homem que vive na Amazônia. É um homem de olhar distante, sem raciocínios, com visão prática, engolido pelo meio, que o faz “[...] impassível e mudo, no grande isolamento de sua desventura" (Cunha, 2003, p. 119). E é ao longo do século passado que, gradativamente, as explicações deterministas passam a dividir espaços com visões que identificam o amazônida a partir de seu isolamento. As distâncias que separam a região do restante do país e do continente sulamericano teriam sido as responsáveis pela emersão de uma cultura cabocla, devedora da cosmologia indígena, que universaliza elementos locais para explicar a vida lançando mão das relações com e entre animais, plantas e tempos da natureza (Paes Loureiro, 2001).

\begin{abstract}
Há, no mundo amazônico, a produção de uma verdadeira teogonia cotidiana. Revelando uma afetividade cósmica, o homem promove a conversão estetizante da realidade em signos, por meio dos labores do dia-a-dia, do diálogo com as marés, do companheirismo com as estrelas, da solidariedade dos ventos que impulsionam velas, da paciente amizade dos rios. [...] A cultura amazônica talvez represente, nesse final de século $[X X]$, uma das mais raras permanências dessa atmosfera espiritual em que o estético, resultante de uma singular relação entre o homem e a natureza, se reflete e ilumina a cultura. (Paes Loureiro, 2001, p. 73).
\end{abstract}

A complexidade desta relação já aparecia antes, em meados do século XX, nas reflexões feitas, por exemplo, por Batista (2007) e por Tocantins (1973). Estes intérpretes da Amazônia, que eram também amazônidas, propunham novas formas de agir na natureza, não mais para subvertê-la, mas para compreendê-la e otimizar as interações entre o humano e o ambiente. Tocantins volta-se para o tempo e para as práticas cotidianas do homem na Amazônia, demarcados pelas águas dos rios que no seu ritmo impõem uma dinâmica particular à sociedade: $0 S$ rios lentos e sinuosos de planície, e as grandes distâncias, impõem uma relação próxima com a natureza (Tocantins, 1973). Exemplo disso é a familiaridade com que moradores da cidade Óbidos, no estado do Pará, ainda agora convivem com as cheias periódicas do rio Amazonas. As águas invadem a cidade sem que isso não altere o cotidiano ao ponto de interrompê-lo. Ao invés disso se alteram os espaços de convivência com a construção de marombas ${ }^{3}$. Os espaços internos

3 As marombas são estruturas de madeiras construídas sobre as águas, durante os períodos de cheias. Podem ser passarelas nas ruas ou então mezaninos dentro das casas e lojas, onde são postos móveis e mercadorias a salvo da água. 
de casas e o espaço público das ruas se elevam junto com as águas, postos sobre estrados de madeira que evidenciam "[...] em meio a paisagem as principais interações ou fluxos comunicacionais que delineiam a dinâmica daquela parte da cidade" (Miranda, 2013, p. 115).

Esta relação com o ambiente natural é determinante em todos os aspectos da vida do amazônida: na saúde, na economia, nas relações sociais, no povoamento da extensa região e nas práticas cotidianas. Mesmo os momentos reconhecidos como de maior desenvolvimento econômico e urbano da região, como os dois ciclos da borracha - entre as décadas de 1870 e 1940 -, estão profundamente atravessados pela relação e pela ação da e na natureza (Tocantins, 1973; 1982).

É neste ambiente que a ideia de um desenvolvimento autossustentado, que implique o reconhecimento das demandas da natureza para então se pensar as ações do homem é foco da atenção de Djalma Batista, que nomina a Amazônia como um complexo em que se cruzam rios, florestas, campos, estradas, interesses econômicos e tradições milenares. Batista tem entre suas preocupações o homem do interior da região, aquele que tem poder aquisitivo mínimo e educação formal deficiente e mal orientada, em flagrante contraste com condições de vida presentes em centros urbanos. Neste cenário Batista (2007) propõe alternativas, e apresenta os meios de comunicação como um dos elementos capazes de permitir a superação das distâncias e do isolamento. Para ele a Amazônia precisa ser decifrada, tal como uma esfinge, sob pena de devorar os homens que nela estão (Batista, 2007).

Se houve ao longo da penetração e fixação do homem na Amazônia do século $X V$ ao século $X X$ - mudanças na maneira como a região é vista, e como se dá a interação entre os homens e destes com a natureza, uma das mais significativas é a progressiva compreensão de que a natureza não é obstáculo para o homem. Ela deve ser compreendida para que então o homem possa nela atuar. Mas, ainda assim há uma permanência: a ideia de separação entre o ser humano e o ambiente natural. As principais implicações desta separação se revelam nas abordagens da natureza como algo externo ao homem, numa constante dicotomização.

\section{Conhecimento complexo, instável e intersubjetivo}

Para alcançar uma abordagem que considere a inseparabilidade de homem e natureza partimos do pressuposto moraniano de que, por exemplo, a essência de uma moeda não é ser "cara ou coroa", como costuma fazer crer a perspectiva mais tradicional do olhar (Morin, 1987). Uma moeda é "cara e coroa" 
assim como nosso olhar nos aponta que um ecossistema é comunicacional por essência e tem no fato de ser comunicacional a axiomática razão de existir apenas como uma perspectiva do olhar, o que torna possível postular um "novo jeito" de olhar o mundo dos amálgamas, das interconexões, dos "nós" que são ao mesmo tempo pronome e substantivo.

Esta dupla implicação pode ser percebida já nas aproximações, ligações e implicações entre o ser humano e o meio natural na Amazônia feitas por vários de seus intérpretes, como Tocantins $(1973,1982)$ e Batista (2007). Já nessas interpretações os posicionamentos eram indicativos da inseparabilidade entre homem e natureza, ainda que os limites epistemológicos necessários de serem então observados não permitissem a superação da abordagem dual que os toma de maneira necessariamente distintiva. De fato, os primeiros movimentos nesta direção se dão a partir do século XIX, ainda longe do continente latinoamericano, e é principalmente a partir das primeiras décadas do século XX que tal separação passa a ser questionada, na Europa e na América do Norte, tendo como consequência transformações - lentas, mas constantes - nos estatutos epistemológicos dos mais diferentes campos disciplinares.

A perspectiva da separação entre o ser humano e a natureza se configura na forma de produzir conhecimento - tanto científico como do senso comum -, desde o século XVII, a partir de modelos que pretendem apresentar a tradução de um mundo dado, independente da percepção sensorial, princípio que leva à procura por um fundamento absoluto capaz apresentar explicações. Este modo de conhecer foi inaugurado, nos moldes como chegou até nós, por René Descartes, e tem sua gênese no modelo consagrado a partir do arcabouço formado pelas descobertas de Copérnico, Newton e Galilei, que implica a observação e a busca por mecanismos que regem a natureza (Wallerstein, 1996). É a fuga do caos, e para que isso seja possível é preciso admitir e conhecer as estabilidades, o que só é possível pela existência de um fundamento fixo para o mundo. A admissão de diferentes realidades, capaz de colocar por terra a ideia de uma realidade dada que possa ser informada - de preferência eliminados os ruídos - leva ao receio de que tudo possa desmoronar para o obscurantismo: "[...] este sentimento de obscuridade surge da ansiedade cartesiana e do seu ideal da mente como espelho da natureza" (Varela, Thompson, Rosch, 2001, p. 191).

A descoberta do mundo quântico questionou os fundamentos físicos do pensamento voltado para uma natureza estável e traduzível em teorias capazes de explicar o funcionamento do universo. A dúvida, a incerteza e a complementaridade que distanciam a ciência da possibilidade de explicações 
totalizantes acabaram por aproximar cientistas das mais diferentes disciplinas, da física à sociologia, de propostas de ligação entre corpo e mente, e do humano com a natureza. A ideia de uma necessária ligação foi, gradativamente, sendo ultrapassada pela complexidade que implica não somente a aproximação, mas a inseparabilidade entre natureza e humanidade (Morin, 1987).

Não há um consenso sobre propostas que tratam da passagem de um estágio paradigmático para outro, mas é inegável a existência de teorias que, no conjunto, apontam para mudanças significativas nos estatutos epistemológicos sobre os quais se assenta a ciência contemporânea. Numa síntese, é possível apontar para ultrapassagens que levam cientistas a considerar - a partir de diferentes abordagens - a passagem da ciência alicerçada sobre pressupostos de simplicidade, estabilidade e objetividade, para novos pressupostos, que consideram complexidade, instabilidade e intersubjetividade. Tal ultrapassagem implica que o conhecimento calcado em relações causais lineares (simplicidade), reversibilidade e controlabilidade (estabilidade), e que tomam o universo como uno e passível de ser explicado objetivamente (objetividade), agora tem um contraponto no conhecimento científico que admite a contextualização e relações causais recursivas (complexidade), a indeterminação, imprevisibilidade, irreversibilidade (instabilidade) e, ao invés da ideia de universo, a de multiverso, em que a objetividade é posta entre parênteses (intersubjetividade) (Vasconcellos, 2012, p. 102).

A percepção que de agimos sobre uma realidade estável se dá não pelo princípio de que a realidade existe independente do observador, mas por uma sensação de estabilidade e pela ideia de realidade construída na interação entre grupos que compartilham as mesmas experiências subjetivas e com isso criam espaços consensuais. $\mathrm{E}$ o consenso na percepção do mundo, que tem na linguagem sua principal expressão, é fundamental para a interação. "Nossa sociedade se organiza com base em consensos estabelecidos em relação aos diversos domínios de experiências - religiosas, ideológicas, morais, legais etc., cada um definido pelo operar de seus observadores, com suas coerências operacionais" (Vasconcellos, 2012, p. 140).

Aolançar mão de termos como"observadores"e "coerências operacionais", Vasconcellos (2012) remete à Biologia do Conhecer, denominação sob a qual são postas as ideias do biólogo chileno Humberto Maturana, que num desdobramento as apresenta em conjunto com o também biólogo chileno Francisco Varela. A teoria que daí resulta tem bases na biologia, mas extrapola um campo do conhecimento em particular e propõe não só a aproximação entre o que é reconhecido como domínios da física e da biologia, mas também destas 
disciplinas com a história e a sociologia. É nossa percepção de que estas ideias podem ser a base para uma chave de compreensão das interações homemnatureza sem recair em posições dicotomizantes, ou mesmo num holismo simplificador.

\section{Atuação corporalizada}

Uma vez que pensamos ser necessário ultrapassar as posições que se constituem a partir da ideia de uma realidade exterior e dada, para alcançar a ideia de inseparabilidade entre homem e natureza é necessário problematizar o conceito de representação, tal como apontaram Maturana e Varela (1995). Para isso consideramos produtivo lançar mão do conceito de enação ${ }^{4}$, que preconiza não a separação entre o ser humano e o ambiente, mas a atuação do indivíduo cognoscente com o ambiente.

Para Varela a representação pressupõe um mundo pré-estabelecido, que deve ser apreendido por meio de diferentes mecanismos e códigos a fim de se tornar inteligível ao ser cognoscente. O autor reconhece a complexidade da representação e esclarece que não a considera estática, mas argumenta que mesmo o reconhecimento de pormenores dinâmicos que a distanciam a ideia de ser apenas um espelho da realidade não permitem deixar de considerá-la “[...] como sendo um processo de recuperação ou de reconstrução de características do meio independentes e extrínsecas" (Varela, Thompson, Rosch, 2001, p. 183). A enação é então uma opção à representação, por tomar a realidade não como preestabelecida, mas o ser cognoscente como inseparável do ambiente e ambos em coatuação. A explicitação da enação passa necessariamente pela apreensão de três conceitos apresentados por Maturana e Varela em obra conjunta (Maturana, Varela, 1995): autopoiese, clausura operacional e acoplamento estrutural.

O conceito de autopoiese foi proposto por Maturana nos últimos anos da década de 1960 e compreende a percepção a partir do operar do sistema nervoso como rede circular fechada de correlações internas. Isso implica a compreensão de que "[...] a organização do ser vivo se explicava [explica] a si mesma ao ser vista como um operar circular fechado de produção de componentes que produziam a própria rede de relações de componentes que

4 Tal como destacado por Varela e colaboradores o termo deriva do inglês enact, com o sentido de atuar, desempenhar um papel em um palco (Varela e outros, 2001). Em outro lugar Varela explicita esta derivação: "Enacción es um neologismo, inspirado del inglés corriente en vez del griego como lo es la autopoiesis [Enação é um neologismo, inspirado do inglês corrente ao invés do grego como é a autopoiesis]" (Varela, 1998, p. 56) (tradução da autora). 
os gerava" (Behncke, 1995, p. 39). Para Maturana a autopoiese caracteriza os seres vivos como unidades autônomas que tem como única função produziremse a si mesmos: "O ser e o fazer de uma unidade autopoética são inseparáveis, e esse constitui seu modo específico de organização" (Maturana, Varela, 1995, p. 89). Um ser vivo surge com o início do processo de autopoiese, e segue vivo até que não seja mais possível a manutenção das condições autopoiéticas. As interações com o ambiente, fundamentais para a conservação da autopoiese, são perturbações que desencadeiam mudanças estruturais exigindo adaptações ao meio. "A mudança estrutural contínua dos seres vivos com a conservação de sua autopoiese ocorre a cada instante, continuamente e de várias maneiras ao mesmo tempo. É o pulsar de tudo o que vive" (Maturana, Varela, 1995, p. 136).

Este autofazer-se implica numa clausura operacional, ou "fechamento" do ser vivo, que torna possível as mudanças provocadas pelas interações com o ambiente sem que se perca a organização de seus componentes. Isso permite que o sistema nervoso constitua-se "[...] de tal forma que, sejam quais forem as mudanças, estas gerem outras mudanças dentro de si mesmo" (Maturana, Varela, 1995, p. 193). É esta característica de fechamento das operações relativas à autopoiese do organismo que permite o equilíbrio da percepção sensorial com uma resposta interna, como quando involuntariamente reagimos a uma repentina mudança de temperatura com um arrepio na pele: "[...] em princípio, toda conduta é uma visão externa da dança de relações internas do organismo" (Maturana, Varela, 1995, p. 194).

As perturbações entre o organismo e o meio são recíprocas e provocam mudanças/adaptações nas suas estruturas para que as unidades autopoéticas não se desintegrem - o que significaria o desaparecimento da unidade autopoiética. A essas adaptações os pesquisadores chilenos nomearam acoplamento estrutural. Para eles há uma história das mudanças estruturais das unidades autopoéticas para interação com o ambiente, e esta é sua ontogenia. Mas, não é a perturbação que determina o que irá acontecer com o organismo, mas a resposta dada pela estrutura do organismo perturbado. Desta maneira não é possível falar de determinação, mas de um desencadear de efeitos causados pelo agente perturbador.

Importante destacar que mesmo havendo uma estrutura não há um dentro e um fora, um limite marcado pela membrana celular ou pela pele, por exemplo, que determine o que é exterior e interior. O que pode ser visto como limite é um elemento de comunicação que faz a interação entre o organismo e o ambiente. Desta maneira, e em função do acoplamento estrutural do organismo com o meio, somente um observador externo poderá fazer a distinção entre 
um e outro. Para o meio e para o organismo não haverá distinção, um não é fonte de instrução para o outro. O organismo - ou unidade, como preferem Maturana e Varela - e o meio, são mutuamente fontes de perturbação um para o outro, e é desta forma que se dá a interação, numa relação em que o equilíbrio é fundamental (Maturana, Varela, 1995).

Os três conceitos explicitados nos aproximam da concepção de que organismos e conjuntos de organismos voltam-se para si mesmos na sua operação, ao mesmo tempo em que nos afastamos das definições que apontam para mecanismos externos de controle. Quando nos voltamos para a cognição humana, que é o ponto central ao tratarmos de interações, assumir o fechamento operacional implica o reconhecimento de que não há um operar a partir da representação. Ao invés disso os organismos autopoéticos, fechados operacionalmente e interagindo por acoplamento estrutural uns com os outros e com o ambiente, atuam: "Em vez de representar um mundo independente, actuam um mundo como um domínio de distinções que é inseparável da estrutura corporalizada pelo sistema cognitivo" (Varela, Thompson, Rosch, 2001, p. 187).

Esta ação corporalizada não é estranha às populações milenares que habitam a Amazônia, e que tem nas suas cosmologias as chaves para compreensão do mundo e guias para as práticas cotidianas, para a relação com o ambiente, entre os indivíduos e entre grupos sociais. Exemplar destas relações são os Yawalapíti (Viveiros de Castro, 2002), povo indígena do sul da Amazônia que não possui qualquer separação radical entre natureza e cultura ou, de maneira específica, entre o ser humano e os animais. No vocabulário Yawalapíti uma mesma palavra, ipúla, refere-se ao homem, aos animais e aos espíritos. "O traço mais saliente da toxonomia yawalapíti do que chamaríamos seres vivos é a ausência de separação categórica entre os humanos e demais animais. Não existe um conceito correspondente à nossa noção de 'animal (não-humano)"' (Viveiros de Castro, 2002, p. 45-46).

Ao considerar o conceito de enação para compreender as interações, como as dos Yawalapíti, há aí implicações especialmente na maneira como se compreende a interação entre seres humanos. As concepções de comunicação pressupõem a transmissão de informação em algum nível, e esta informação é apresentada por um emissor em forma de símbolos ou signos e direcionada a um receptor. Trata-se de uma ideia que considera um mundo que pode ser representado, e que de alguma maneira a informação já existe, devendo ser organizada e transmitida. É esta concepção que o conceito de enação questiona, pois ao atuar em acoplamento estrutural o ser humano recebe a perturbação 
e retém aquilo que Ihe interessa para manter sua relação com o meio, e com o outro, o mais próximo possível de um nível ótimo. E isto é diferente de apenas receber a informação.

\section{Performance ampliada}

A comunicação, tomada como processo complexo e corporalizado, deve considerar a inseparabilidade entre o ser humano e o ambiente, também a presença cada vez maior das tecnologias no cotidiano do ser humano, elemento que potencializa e reconfigura as interações. Nesta reconfiguração a corporalidade é elemento fundamental, mas agora considerada a tecnologia que modifica os tempos e os espaços. Discípulo de McLuhan, Derrick de Kerckhove mostra como as tecnologias de maneira geral, e as da comunicação em especial, estendem nossas mentes e como isso se deve essencialmente aos efeitos que provocam no corpo e no sistema nervoso, ao ponto de fazer todo o sentido pensar "[...] a pele como dispositivo de comunicação e não de proteção [...]" (Kerckhove, 1997, p. 128). A nossa posição é de que esta percepção aproxima suas proposições daquelas apresentadas por Maturana e Varela e do conceito de enação. Os artefatos de comunicação, proporcionados pela crescente sofisticação da tecnologia de comunicação que se firmou a partir do século XX, resultam na proliferação de interfaces sensoriais, prolongamentos de mentes e corpos, dos sentidos, e nos fazem ter um ponto de vista também estendido. Com isso "[...] não é o mundo que se está a tornar global, somos nós" (Kerckhove, 1997, p. 123), numa amplitude que torna possível considerar que o tamanho efetivo de nosso corpo é o tamanho do planeta.

Por esta abordagem o que as tecnologias fazem é potencializar sentidos naturais, a visão e a audição principalmente, com perturbações percebidas pelo sistema nervoso. Entre os argumentos de Kerckhove (1997) está o de que a linguagem, que tornou possível as interações entre seres humanos distantes fisicamente e no tempo - principalmente após o surgimento do alfabeto -, também fez com que nos aprisionássemos dentro de nossos corpos e perdêssemos as conexões com o ambiente. Quanto mais nos aprofundávamos numa cultura voltada para a linguagem transformada em alfabeto, e posta em circulação em suportes cada vez mais sofisticados, mais nos voltávamos para o nosso interior, para o que nossas mentes falavam dentro de nós protegidas pela fronteira em que foi convertida a pele. Quanto mais nos comunicávamos pela linguagem e pelo suporte proporcionado pelo alfabeto, mais esta operação era vista como via preferencial de interação, mais nos apartávamos da ideia de fazer parte do ambiente. Erámos nós aqui e o ambiente lá! 
A realidade virtual proporcionada pela tecnologia, em simuladores dos mais diferentes tipos - e aí é possível listar desde programas de treinamento de pilotos, até redes sociais onde é simulada a amizade, a convivência social e a participação política -, subvertem em larga medida as regras impostas pela linguagem organizada pelo alfabeto, e nos reaproxima da oralidade que implica a proximidade física. Ver, ouvir, reagir aos estímulos de uma tela provoca reações no sistema nervoso que nos fazem assumir que somos partícipes da eclosão de uma nova psicologia, de uma nova relação sensorial. Esta relação é visível, por exemplo, em comunidades do interior da Amazônia em que não foram abandonadas as formas tradicionais de interação, mas a estas se somaram aquelas proporcionadas pelos meios de comunicação, especialmente a televisão, e de maneira crescente pela internet e por aparelhos multiplataformas, como o celular. "Os mitos, as lendas, passam a conviver com as novelas, com o jogo de futebol. Incorpora-se à oralidade resultante das vivências locais uma oralidade que reproduz experiências não vividas localmente" (Cristo, 2012, p. 82). Esta incorporação altera as maneiras de interagir localmente, e a percepção que estas comunidades tem do ambiente.

A interação se expande e passa a ser também "[...] a capacidade que garante a nossa autonomia individual dentro da poderosa tendência da colectivização psicotecnológica, [e] é fornecida pelos computadores e ainda mais eficazmente pelas redes de computadores" (Kerckhove, 1997, p. 35). É o caso dos índios Suruí, de Rondônia, que modificaram, pelo suporte tecnológico, as formas de relação com o seu meio e com outros grupos sociais. Desde 2007 os Suruí utilizam equipamentos digitais para denunciar ações de depredação de sua reserva, e estão prestes a negociar créditos de carbono, tudo isso após receberem equipamentos e softwares desenvolvidos pela Google especialmente com esta finalidade (Costa, 2012). Esta relação tem significado mudanças no seu modo de vida, ao mesmo tempo em que as tradições são preservadas, como exemplifica o chefe Almir Suruí:

Hoje nós temos outra cultura que é de outro jeito, outro modelo,
mais avançado, mais tecnológico, mais estudado, mais, entendeu?
[...] [Mas] Eu não posso só dar valor ao meu tecnologia, se eu não dar
valor ao meu colar. Então um exemplo disso tá aqui, eu tô usando
meu Mac e também tô usando meu colar, tá ali (na parede) meu
cocar quando uso, tá ali (na parede) meu arco e flecha. (Almir Suruí,
in: Costa, 2012, p. 93).

As relações sociais mudam a cada nova tecnologia desenvolvida e incorporada pelos seres humanos, e estas mudanças são em larga medida 
provocadas pelo ajuste entre os artefatos tecnológicos e os seus utilizadores, de maneira que possa haver a interação entre as instâncias psicológica e técnica. As mediações entre o sistema nervoso e os sistemas tecnológicos são possíveis pelas interfaces produzidas pelo design, e proporcionam uma relação entre homens e máquinas similar àquelas apontadas por Maturana e Varela (1995) quando tratam do acoplamento estrutural. Há uma plasticidade necessária para o acoplamento entre o ser humano no seu ambiente, e para o uso de artefatos tecnológicos. A esta interação biotécnica estreita Kerckhove chama de psicotecnologias, uma vez que se alteram as maneiras do sistema nervoso perceber o mundo. As psicotecnologias "[...] mudam relações no tecido social, reestruturam ou modificam também aspectos psicológicos, especialmente aqueles que dependem da interacção entre linguagem e o organismo humano ou entre a mente a máquina" (Kerckhove, 1997, p. 275).

Maturana e Varela tratam da plasticidade estrutural como elemento fundamental para a interação entre um organismo e o ambiente, e também para as relações autopoiéticas do organismo:"[...] o sistema nervoso, ao participar por meio dos órgãos sensoriais e efetores dos domínios de interação do organismo que selecionam a mudança estrutural deste, participa da deriva estrutural do organismo com conservação de sua adaptação" (Maturana, Varela, 1995, 194). Sem ter sido produzido por ninguém o organismo, o sistema nervoso, é resultado de mudanças que ocorrem durante sua ontogenia, é resultado de sua interação com o meio e das suas próprias necessidades. O design de que trata Kerckhove (1997) considera o sistema nervoso, mas trata de máquinas construídas pelo ser humano para interagir com ele e com o ambiente. $O$ encaixe é realizado por um design que permita a interação. “O design [...] é uma modulação da relação entre o corpo e o ambiente na medida em que ela é modifica pela tecnologia. A tecnologia vem do corpo humano e o design dá-Ihe sentido" (Kerckhove, 1997, p. 214-215).

A partir daí Kerckhove propõe a ideia de um ciberdesign, a modulação entre humanos e tecnologia, que se apresenta de maneira tão eficiente que acaba por não ser mais percebida, ao ponto do encaixe - ou como podemos pensar, o acoplamento estrutural - não ser detectado e por isso seguir inquestionado. "Quando o design se torna na interface normalizada entre o pensamento e a acção, as atividades dependentes do pensamento e do planeamento podem tornar-se extensões directas do pensamento e da sensibilidade" (Kerckhove, 1997, p. 142-143). É assim que as interações entre tecnologia e seres humanos, e destes com o ambiente, alteram as relações espaço-temporais, que se complexificam, e junto com elas as relações interpessoais e com o ambiente. 
Exemplar é o caso dos Ashaninkas, povo indígena que ocupa regiões no sudoeste do estado do Acre. Na sua cosmologia não há a separação entre o humano e o não-humano, e aí devem ser considerados os rios, a floresta, e toda a fauna e a flora. Esta profunda percepção de mútua implicação é impactada pela presença de computadores com acesso à internet e pela crescente presença de telefones celulares. Mas, ao contrário de significar a substituição da percepção de si como parte da natureza, para os Ashaninkas a tecnologia surgiu como possibilidade de

[...] disseminação de seus saberes tradicionais baseada em sua relação sustentável com a natureza, a visibilidade de sua diferença e a promoção de ações em rede entre essas comunidades e na rede pelos circuitos digitais. Deslocam a Floresta e seus povos para o mundo, possibilitando a transmissão de sua atmosfera ambiental e o diálogo intercultural com outras redes de apoio além das historicamente existentes. (Pereira, 2013, p. 15).

O que emerge daí são interações recursivas e dialógicas que se mostram complexas, assim como são complexas as interações entre os organismos e seus ambientes. São relações são corporais amplificadas pela tecnologia que nos permitem admitir maneiras de conhecer em que a complexidade, a indeterminação e a intersubjetividade são mais do que apostas.

\section{Inquietantes acoplamentos dérmicos}

Mesmo que consideremos, e é isso que efetivamente fazemos, que são raros os grupos humanos que não tem qualquer contato com os modos contemporâneos de interação, e aí está implicada a relação com os meios de comunicação - os programas oficiais de eletrificação e telefonia rural, as antenas parabólicas, o sinal de internet disponibilizado via satélite, e mesmo a transmissão de rádio em ondas curtas, são exemplos das possibilidades de superação das condições de isolamento no interior da Amazônia -, fora das grandes zonas urbanas e das áreas de colonização agrícola recente na Amazônia o que se encontra na região são práticas cotidianas estreitamente ligadas a memórias culturais e pragmáticas que tem suas bases nas cosmologias indígena e cabocla. Isso implica um reconhecimento de si ligado à natureza de maneira inapartável.

Diante disso como atua o pesquisador, dada a complexa relação entre natureza e com as tecnologias? O que acontece com o amazônida que passa de uma condição de isolamento imposto pela natureza para um mundo de conexões potencialmente ilimitadas? Uma vez que as interações consideradas 
a partir do conceito de enação possam ser pensadas também para a interação mediada pela tecnologia, o ser humano que em alguma medida saltou o estágio de profunda ligação com o mundo representado - a exemplo do amazônida -, terá maiores e melhores possibilidades de chegar a um nível ótimo no uso das tecnologias que proporcionam a comunicação em rede?

$\mathrm{Na}$ reflexão de Kerckhove, quando grupos sociais são submetidos a mudanças as respostas vem em padrões emergentes de assimilação, integração, alienação ou agressão, ou seja, altera-se a forma de agir desta sociedade. Se as respostas até então eram dadas pela agressão, na mudança elas vêm na mesma intensidade, com as mesmas características de participação coletiva, mas se alteram para tornar possível outro tipo de ação. O que era agressão pode ser agora trabalho, como ocorreu no Japão. "Depois de terem tido um formidável impulso de agressividade na Segunda Guerra Mundial, os japoneses encontraram uma nova resposta: mudar de pele" (Kerckhove, 1997, p. 221). As mudanças se dão na pele, no ponto de contato entre o indivíduo com o grupo social e deste com os demais grupos sociais. Há aí um acoplamento, a partir de uma perturbação, que leva à adaptação a fim de que seja possível manter o conteúdo, a plasticidade da cultura que caracteriza aquele grupo e cria consenso entre os seus membros.

Neste ponto é possível pensar que a tecnologia posta à disposição de amazônidas que mantém profundo senso de mútua implicação e coatuação com a natureza também implica profunda mudança nas relações. Mas, não uma mudança que altere as relações e práticas organizadas a partir do senso de inseparabilidade entre os seres humanos e a natureza que, em larga medida, caracteriza estes grupos sociais. Diferente disso, é o princípio de inseparabilidade que pode otimizar a atuação com o ambiente agora também tecnológico.

Esta é a via por onde levamos nossas inquietações.

\section{Referências}

BATISTA, Djalma. O complexo da Amazônia - Análise do processo de desenvolvimento. 2 ed. Manaus: Editora Valer, Edua e Inpa, 2007.

BEHNCKE, Rolf C. Ao pé da árvore - prefácio. In: MATURANA, Humberto; VARELA, Francisco. A árvore do conhecimento: as bases biológicas do entendimento humano. São Paulo: Editorial Psy II, 1995.

COSTA, Tamiles do Espírito Santo. Amazônicos e Tecnológicos: os Suruís de Rondônia e suas articulações globais. Dissertação (Mestrado em Comunicação, Cultura e Amazônia). Universidade Federal do Pará, Belém: 2012. 
CRISTO, Élida Fabiani de. Oralidade em uma comunidade amazônica: comunicação, cultura e contemporaneidade. Dissertação (Mestrado em Comunicação, Cultura e Amazônia). Universidade Federal do Pará, Belém: 2012.

CUNHA, Euclides. Amazônia - Um paraíso perdido. Manaus: Editora Valer/Governo do Estado do Amazonas/Editora da Universidade Federal do Amazonas, 2003.

KERCKHOVE, Derrick de. A pele da cultura - Uma investigação sobre a nova realidade eletrônica. Tradutor: Luís Soares e Catarina Carvalho. Lisboa: Relógio D’Água Editores, 1997.

LOUREIRO, João de Jesus Paes. Cultura amazônica - uma poética do imaginário. São Paulo: Escrituras Editora, 2001.

MATURANA, Humberto; VARELA, Francisco. A árvore do conhecimento: as bases biológicas do entendimento humano. São Paulo: Editorial Psy II, 1995.

MIRANDA, Fernanda Chocron. Cartografia Movente: uma postura de pesquisa em comunicação na Amazônia. Dissertação (Mestrado em Comunicação, Cultura e Amazônia). Universidade Federal do Pará, Belém: 2013.

MORIN, Edgar. 0 método 1 - Da natureza da natureza. Trad.: Maria Gabriela de Bragança. 2a. ed. Mem Martins: Publicações Europa-América, 1987.

PEREIRA, Eliete da Silva. O Centro Yorenka Ãtame e a ecologia xamânica comunicativa Ashaninka. XXXVI Intercom - Congresso Brasileiro de Ciências da Comunicação. 2013, Manaus-AM. Anais... São Paulo-SP: Intercom, 2013.

PINTO, Renan Freitas. Viagem das idéias. 2a. ed. Manaus: Editora Valer, 2008.

PORTO-GONÇALVES, Carlos Walter. Amazônia, amazônias. 2 ed., São Paulo: Contexto, 2005.

SURUÍ, Almir. Íntegra da entrevista feita com Almir Suruí. In: COSTA, Tamiles do Espírito Santo. Amazônicos e Tecnológicos: os Suruís de Rondônia e suas articulações globais. Dissertação (Mestrado em Comunicação, Cultura e Amazônia). Universidade Federal do Pará, Belém, 2012.

TOCANTINS, Leandro. 0 rio comanda a vida - Uma interpretação da Amazônia. Rio de Janeiro: Biblioteca do Exército, 1973.

. Amazônia: natureza, homem e tempo. 2 ed., Rio de Janeiro: Biblioteca do Exército: Ed. Civilização Brasileira, 1982.

VARELA, Francisco; THOMPSON, Evan; ROSCH, Eleanor. A mente corpórea - ciência cognitiva e experiência humana. Lisboa: Piaget, 2001.

VASCONCELLOS, Maria José Esteves de. Pensamento sistêmico: o novo paradigma da ciência. 9 ed., Campinas: Papirus, 2012. 
VIVEIROS DE CASTRO, Eduardo. Esboço de cosmologia yawalapíti. In: A inconstância da alma selvagem e outros ensaios de antropologia. São Paulo: Cosac \& Naify, 2002.

WALLERSTEIN, Immanuel e outros. Para abrir as ciências sociais. São Paulo: Cortez, 1996.

Recebido em: 22/04/2015

Aceito em: 9/09/2015

Endereço dos autores:

Sandro Adalberto Colferai <sandrocolferai@gmail.com>

Universidade Federal do Amazonas (UFAM)

Av. General Rodrigo Octávio, 6200 - Coroado I

CEP: $69077-000$

Manaus, AM - Brasil

Gilson Vieira Monteiro <gilsonvieiramonteiro@yahoo.com>

Universidade Federal do Amazonas (UFAM)

Av. General Rodrigo Octávio, 6200 - Coroado I

CEP: 69077-000

Manaus, AM - Brasil 